Keywords: radiation-induced bystander effects (RIBEs); TGF- $\beta 1$ signalling pathway; miR-21; reactive oxygen species (ROS); lung cancer cells

\title{
The role of TGF- $\beta 1-$ miR-21-ROS pathway in bystander responses induced by irradiated non-small-cell lung cancer cells
}

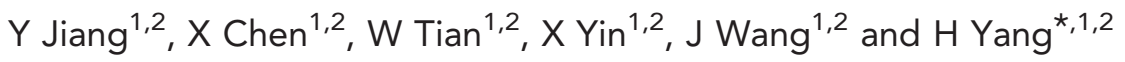 \\ ${ }^{1}$ School of Radiation Medicine and Protection, Medical College of Soochow University/School for Radiological and \\ Interdisciplinary Sciences (RAD-X), Soochow University, 199 Renai Road, Suzhou Industrial Park, Suzhou, Jiangsu Province \\ 215123, China and ${ }^{2}$ Collaborative Innovation Center of Radiation Medicine of Jiangsu Higher Education Institutions and School for \\ Radiological and Interdisciplinary Sciences (RAD-X), Soochow University, Suzhou 215123, China
}

Background: Many studies have indicated an important implication of radiation-induced bystander effects (RIBEs) in cancer radiotherapy, but the detailed signalling remains unclear.

Methods: The roles of tumour growth factor-beta1 (TGF- $\beta 1$ ) and miR-21 in medium-mediated RIBEs in H1299 non-small-cell lung cancer cells were investigated using DNA damage, changes in proliferation and levels of reactive oxygen species (ROS) as end points. SB431542, a specific inhibitor of TGF- $\beta$ type 1 receptor kinases, was used to inhibit TGF- $\beta 1$ pathways in irradiated and bystander cells. Exogenous miR-21 regulation was achieved through inhibitor or mimic transfection.

Results: Compared with relative sham-radiation-conditioned medium, radiation-conditioned medium (RCM) from irradiated cells $1 \mathrm{~h}$ post radiation (1-h RCM) caused an increase in ROS levels and DNA damage in bystander cells, while 18-h RCM induced cell cycle delay and proliferation inhibition. All these effects were eliminated by TGF- $\beta$ R1 inhibition. One-hour RCM upregulated miR-21 expression in bystander cells, and miR-21 inhibitor abolished bystander oxidative stress and DNA damage. Eighteen-hour RCM downregulated miR-21 of bystander cells, and miR-21 mimic eliminated bystander proliferation inhibition. Furthermore, the dysregulation of miR-21 was attenuated by TGF- $\beta R 1$ inhibition.

Conclusions: The TGF- $\beta 1-$ miR-21-ROS pathway of bystander cells has an important mediating role in RIBEs in H1299 cells.

The traditional dogma claims that biological effects of ionising radiation require direct damage to DNA. However, the occurrence of radiation-induced bystander effects (RIBEs) challenges this dogma. RIBEs refer to the biological responses occurred in unirradiated cells through intercellular communication when the neighbouring cells are traversed by ionising radiation. RIBEs have attracted an intense interest since 1992, when Nagasawa and Little (1992) provided direct evidence for the existence of this effect. To date, RIBEs have been demonstrated both in vitro (Azzam et al, 2001; Zhou et al, 2001; Lyng et al, 2002; Shao et al, 2004; Yang et al, 2005) and in vivo (Koturbash et al, 2006; Mancuso et al, 2008; Jain et al, 2011). Besides normal cells, cancer cells have recently been found to express RIBEs (Burdak-Rothkamm et al, 2007; Harada et al, 2009; Rzeszowska-Wolny et al, 2009; Herok et al, 2010). Moreover, a recent study (McMahon et al, 2013) suggests that bystander effects may be essential in producing a robust decrease in cancer cell survival in directly irradiated populations. Another study (Aravindan et al, 2014) strongly suggests that acquired tumour cell radiation resistance at the treatment site is mediated through radiation-orchestrated intercellular communication. All these results indicate a potential important clinical implication of bystander effects in the context of radiotherapy.

Although the existence of RIBEs has been well recognised and documented, the underlying molecular mechanisms are poorly 
understood. So far, intercellular gap junctions (Azzam et al, 2001; Zhou et al, 2001), reactive oxygen species (ROS) (Azzam et al, 2002; Yang et al, 2005) and soluble signalling molecules such as cytokines (Ivanov et al, 2010; Hei et al, 2011) have been demonstrated to mediate bystander response. Among cytokines, tumour growth factor-betal (TGF- $\beta 1$ ) has been found to be an important mediator of bystander effects (Iyer et al, 2000; Shao et al, 2008; Gow et al, 2010; Temme and Bauer, 2013). However, the detailed mechanisms for how TGF- $\beta 1$ mediates RIBEs remain to be elucidated.

It has recently been proposed that bystander effects may be epigenetically mediated (Kovalchuk and Baulch, 2008; Ilnytskyy and Kovalchuk, 2011; Mothersill and Seymour, 2012). microRNAome changes have been demonstrated in bystander cells and tissues (Koturbash et al, 2007, 2008; Kovalchuk et al, 2010; Chaudhry and Omaruddin, 2012), suggesting the involvement of miRNA modulation in RIBEs. However, through miRNA knockdown, Dickey et al (2011) found no difference in DNA damage in bystander cells between wild type and knockdown cells with depleted levels of mature miRNAs, suggesting that miRNAs were not the primary signalling factor in the induction of bystander effect, although they had a role in RIBE manifestation. Thus, the roles of miRNAs in bystander signalling need to be further explored.

In the present study, we investigated the roles of TGF- $\beta 1$ and miR-21 in medium-mediated RIBEs in H1299 human non-smallcell lung cancer cells. We found that different biological changes were induced in bystander cells at different times post radiation. The TGF- $\beta 1$ signalling pathways in both irradiated and bystander cells were critical to the induction of RIBEs. TGF- $\beta 1$-dependent ROS appeared to be involved in early but not in late bystander responses. We also found that miR-21 in bystander cells was regulated by the TGF- $\beta 1$ pathway and was an important mediator of bystander signalling.

\section{MATERIALS AND METHODS}

Cell culture and irradiation. H1299 cells were purchased from the Cell Bank of Chinese Academy of Sciences (Shanghai, China). The cells were cultured in RPMI1640 (Sigma Aldrich, St Louis, MO, USA) supplemented with $2.5 \mathrm{gl}^{-1}$ of glucose, $10 \%$ fetal bovine serum (Hyclone, Waltham, MA, USA), $1 \mathrm{~mm}$ sodium pyruvate (Sigma Aldrich), $100 \mathrm{U} \mathrm{ml}^{-1}$ penicillin, $100 \mu \mathrm{g} \mathrm{ml}^{-1}$ streptomycin (both from Beyotime Institute of Biotechnology, Haimen, China) and $1 \mathrm{~mm}$ HEPES (pH 7.2, Robiot, Nanjing, China), and were maintained in a humidified atmosphere of $95 \%$ air $/ 5 \% \mathrm{CO}_{2}$ at $37^{\circ} \mathrm{C}$. Cells were irradiated with $160 \mathrm{kVp}$ $\mathrm{X}$-rays (RAD SOURCE RS2000 X-ray machine, Suwanee, $\mathrm{GA}, \mathrm{USA}$ ) at a dose rate of $1.16 \mathrm{~Gy} \mathrm{~min}^{-1}$.

Conditioned medium harvest. The medium transfer method was used in this study. Cells were seeded in $100-\mathrm{mm}$ petri dishes. Culture medium was replaced with fresh medium $24 \mathrm{~h}$ later, and cells were irradiated with $5 \mathrm{~Gy}$ X-rays. The cells were cultured for either additional $1 \mathrm{~h}$ or $18 \mathrm{~h}$. The conditioned medium was then harvested and filtered through sterile syringe filters $(\Phi 0.22 \mu \mathrm{m})$ to remove any suspended cells. For convenience, irradiated cells eliciting bystander signals are referred to signalling cells, and unirradiated cells cultured in conditioned medium are referred to bystander cells in the text. The radiation-conditioned media harvested from irradiated cells at $1 \mathrm{~h}$ and $18 \mathrm{~h}$ post irradiation are referred to 1 -h radiation-conditioned medium (RCM) and 18-h $\mathrm{RCM}$, respectively. The corresponding control is referred to sham-radiation-conditioned medium (SCM). In addition, the experiments included samples cultured in fresh medium (Ctr).

TGF- $\beta 1$ inhibition with SB431542. To inhibit the TGF- $\beta 1$ pathway in signalling cells, SB431542 $(10 \mu \mathrm{M})$, a potent and selective inhibitor of TGF- $\beta 1$ receptor kinases, was added to signalling cells $1 \mathrm{~h}$ before irradiation, and immediately after radiation, the medium was replaced with fresh medium. To inhibit the TGF- $\beta 1$ pathway in bystander cells, SB431542 was added directly into conditioned medium before it was transferred to bystander cells.

Immunofluorescence for p53-binding protein 1 foci and 8-hydroxy-2'-deoxyguanosine. H1299 cells were seeded on coverslips. Twenty-four hours later, cells were treated with different medium for $1 \mathrm{~h}$. The cells were then fixed in 3.7\% formaldehyde (Sigma Aldrich) and stained as previously described (Yang et al, 2011). Briefly, the cells were sequentially incubated with anti-p53binding protein 1 (53BP1) antibody (Abcam, Cambridge, UK) at $1: 200$ and with Alexa Flour 488-conjugated goat anti-rabbit secondary antibody at $1.5 \mu \mathrm{g} \mathrm{ml}^{-1}$ (Invitrogen, Carlsbad, CA, USA) after blocking. The cells were counter stained with $10 \mu \mathrm{g} \mathrm{ml}^{-1} 4^{\prime}, 6^{\prime}$-diamidimo-2-phenylindole (Beyotime, Haimen, China) and mounted with Antifade Mounting Medium (Beyotime). The cells were then scored under a fluorescent microscope (Leica DM 2000, Leica Microsystems, Shanghai, China). The cells containing at least five 53BP1 foci were considered positive cells. At least 500 cells in at least 10 fields were examined for each sample.

8-hydroxy-2'-deoxyguanosine detection was performed as previously described (Moiseeva et al, 2009). In brief, bystander cells were fixed with $4 \%$ paraformaldehyde for $15 \mathrm{~min}$ at room temperature (RT) after treatment with conditioned medium. Then cells were sequentially incubated with $2 \mathrm{M} \mathrm{HCl}$ for $20 \mathrm{~min}$ and $0.1 \mathrm{~mm}$ sodium borate ( $\mathrm{pH} 8.5$ ) for $2 \mathrm{~min}$ at RT. After wash, cells were permeabilized and incubated with primary antibody against 8-hydroxy-2'-deoxyguanosine (Abcam) overnight at $4{ }^{\circ} \mathrm{C}$, followed by incubation with secondary antibody. Then cells were counter stained with 4', 6'-diamidimo-2-phenylindole and mounted on slides. The fluorescence intensity of at least 100 cells was recorded using TCS SP2 Laser Scanning Confocal Microscope (Leica, Solms, Germany), the data were analysed with the Leica-SP2 quantification software (Leica Microsystems). Cells treated with $100 \mu \mathrm{M} \mathrm{H}_{2} \mathrm{O}_{2}$ were used as positive control.

Crystal violet assay. Cells were seeded in 96-well plates at a density of 5000 cells per well. The medium was replaced with different conditioned medium $24 \mathrm{~h}$ later, and the cells were cultured for different times $(24,48$ or $72 \mathrm{~h}$ ). Then the medium was carefully aspirated from wells, and the cells were washed and stained with crystal violet solution (0.5\%) in methanol for $15 \mathrm{~min}$ at RT. Then, the cells were destained with tap water and allowed to air dry. The dye was eluted with $100 \mu \mathrm{l}$ of $0.1 \mathrm{M}$ sodium citrate ( $\mathrm{pH} 4.2) / 50 \%$ ethanol for $30 \mathrm{~min}$ at RT. Absorbance at $540 \mathrm{~nm}$ was measured with a plate reader (BIO-TEK PowerWave XS, Winooski, VT, USA). All results were normalised with the cells cultured in fresh medium at relative time points.

Flow cytometry analysis. H1299 cells were seeded in 60-mm petri dishes. Twenty-four hours later, cells were cultured with different conditioned medium for 24,48 or $72 \mathrm{~h}$. Then the cells were harvested and fixed with ice-cold $70 \%$ ethanol, and stored at $-20^{\circ} \mathrm{C}$ for at least overnight. The cells were washed and resuspended in phosphatebuffered saline (containing $2 \mu \mathrm{g} \mathrm{ml}^{-1}$ RNAase) and stained with propidium iodide solution $\left(0.1 \mathrm{mg} \mathrm{ml}^{-1}\right)$ for $30 \mathrm{~min}$ on ice. The cells were then analysed for cell cycle distribution using a BECKMAN COULTER CYTOMICS FC 500 flow cytometer (Beckman Coulter, Shanghai, China), and data analysis was performed using Multicycle AV for Windows (Phoenix Flow Systems Inc, San Diego, CA, USA).

Quantification of TGF- $\beta 1$ in conditioned medium by enzymelinked immunosorbent assay. H1299 cells were irradiated with $5 \mathrm{~Gy}$ X-rays $24 \mathrm{~h}$ after plating. The conditioned medium was then harvested 1 and $18 \mathrm{~h}$ later. The amount of TGF- $\beta 1$ in the 
conditioned medium was quantified using the Quantikine ELISA Kit (R\&D Systems, Minneapolis, MN, USA) according to the manufacturer's instructions. Before the assay, any latent TGF- $\beta 1$ was activated with $1 \mathrm{M} \mathrm{HCl}$, and acid was neutralised with $1.2 \mathrm{M}$ $\mathrm{NaOH} / 0.5 \mathrm{M}$ HEPES.

Measurement of intracellular ROS. The production of ROS in bystander cells was measured using the OxiSelect Intracellular ROS Assay Kit (Cell Biolabs, San Diego, CA, USA). Briefly, cells were seeded in a clear 96-well culture plate for $24 \mathrm{~h}$. The medium was replaced with fresh serum-free medium containing $10 \mu \mathrm{M} 2^{\prime}, 7^{\prime}$-dichlorfluorescein-diacetate for $1 \mathrm{~h}$ at $37^{\circ} \mathrm{C}$. After $2^{\prime}, 7^{\prime}$-dichlorfluorescein-diacetate was removed, the cells were cultured with different conditioned medium. At different time points, cell lysis buffer was added to each well, mixed thoroughly, and incubated for $5 \mathrm{~min}$. Then, the mixture was transferred to a 96well plate suitable for fluorescence measurement. The fluorescence at $530 \mathrm{~nm}$ with an excitation wavelength of $480 \mathrm{~nm}$ was measured with a fluorometric plate reader (Synergy2, Winooski, VT, USA). Cells treated with $300 \mu \mathrm{M} \mathrm{H}_{2} \mathrm{O}_{2}$ were used as positive control. Each sample was assayed in triplicate.

Real-time PCR. One hour after cultured with conditioned medium, miRNA from bystander cells was isolated and purified using the E.Z.N.A. miRNA Kit (Omega Bio-tek, Norcross, GA, USA). Reverse transcription was subsequently performed using the TaqMan MicroRNA Reverse Transcription Kit (AB Applied Biosystems, Foster City, CA, USA). Quantitative real-time PCR was performed using TaqMan MicroRNA Assays (AB Applied Biosystems) as described previously (Simone et al, 2009). RNU6B was chosen as the internal control. The PCR results were normalised with RNU6B and expressed as relative expression compared with the untreated control.

Transfection of miRNA mimic and inhibitor. Cells were seeded at an appropriate density so that they were about $70 \%$ confluent at the time of transfection. The negative mimic (NC, sense $5^{\prime}$-UUCU UCGAACGUGUCACGUTT- $3^{\prime}$ and antisense $5^{\prime}$-ACGUGACACG UUCGGAGAATT- $3^{\prime}$ ), miR-2 1 mimic ( $5^{\prime}$-UAGCUUAUC AGAC UGAUGUUGAAACAUCAGUCUGAUAAGCUAUU-3'), negative inhibitor (IN.NC, $5^{\prime}$-CAGUACUUUUGUGUAGUACAA-3'), or miR-21 inhibitor (IN, $5^{\prime}$-UCAACAUCAGUCUGAUAAGCUA-3'), which were purchased from GenePharma (Shanghai, China), were added to the cells at the required final concentration $(0.3 \mu \mathrm{M})$ after mixing with lipofectamine 2000 (Invitrogen) according to the manufacturer's instructions. The medium was replaced with fresh medium $6 \mathrm{~h}$ after transfection, and the cells were assayed for different end points at appropriate times.

Statistical analysis. All data presented in this paper are the average of at least three independent experiments, and the results are shown as the means \pm standard error (s.e.). Differences between the RCM group and SCM group were analysed using the Student's $t$-test of Origin 8 software (OriginLab, Northampton, MA, USA). A $P$-value of $\leqslant 0.05$ between groups was considered significantly different.

\section{RESULTS}

Medium-mediated bystander effects in H1299 cells at different times post irradiation. We detected biological changes in bystander cells cultured in conditioned medium. Figure 1B shows that when cultured in 1 -h RCM for $1 \mathrm{~h}$, there was a significant increase $(41 \%)$ in the percentage of cells with 53BP1 foci (Figure 1A), a surrogate marker of DNA damage (Asaithamby and Chen, 2009), in bystander cells compared with the cells in SCM. However, the increase was not detected when bystander cells were cultured in 18-h RCM. The data indicated the occurrence of DNA damage in bystander cells cultured in 1-h

\section{A}
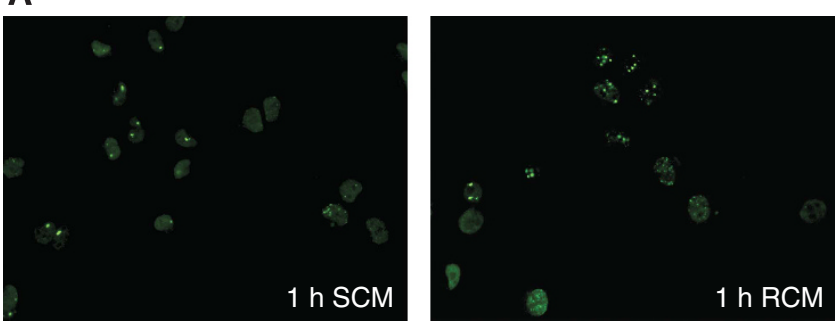

B

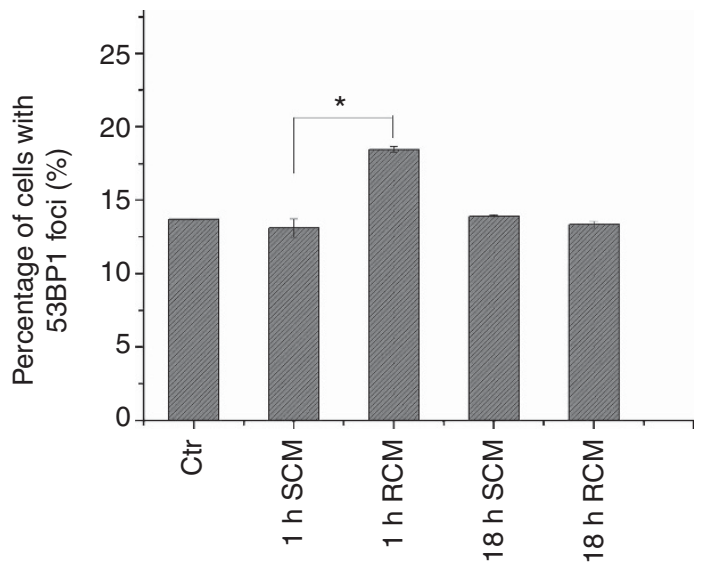

C

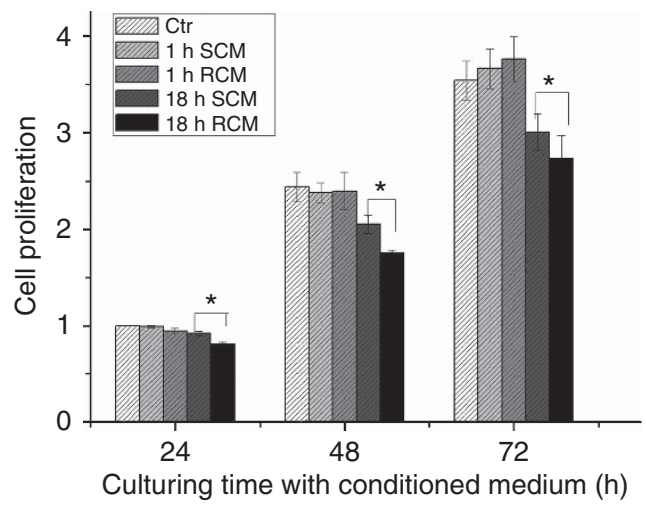

Figure 1. Radiation-induced medium-mediated bystander responses in $\mathrm{H} 1299$ cells cultured in RCM harvested at different times post irradiation. (A) In situ immunofluorescence images of 53BP1 foci in bystander cells; (B) induction of 53BP1 foci in the bystander cells cultured in 1-h RCM; (C) inhibition of cell proliferation in the bystander cells cultured in 18-h RCM. * represents $P$-value $<0.05$ vs relative SCM.

RCM but not in 18-h RCM. However, after cultured in 18-h RCM for 24,48 or $72 \mathrm{~h}$, the proliferation of bystander cells was decreased by $13 \%, 15 \%$ or $9 \%$, respectively, compared with in SCM. In contrast, 1-h RCM did not affect the proliferation of bystander cells (Figure 1C). Furthermore, culture in 18-h RCM for $24 \mathrm{~h}$ induced a significant G2 delay in bystander cells compared with in 18-h SCM (Table 1), suggesting that 18-h RCM probably inhibited cell proliferation by inducing G2 delay. All the results suggested that irradiated H1299 cells may send different signals at different times after irradiation, in turn inducing different biological changes in bystander cells.

The TGF- $\beta 1$ signalling pathway was involved in the bystander response in $\mathrm{H} 1299$ cells. We first measured the amount of TGF- $\beta 1$ in SCM and RCM. We found that compared with the relative SCM, the total amount of TGF- $\beta 1$ decreased in 1 -h RCM and increased in 18-h RCM (Figure 2A). To calculate the amount of TGF- $\beta 1$ released by signalling cells, we subtracted the amount of TGF- $\beta 1$ in fresh medium from the total amount measured, and 


\begin{tabular}{|c|c|c|c|}
\hline & $\begin{array}{l}\text { Untreated } \\
\text { control }\end{array}$ & 18-h SCM & 18-h RCM \\
\hline \multicolumn{4}{|l|}{$24 \mathrm{~h}$} \\
\hline $\begin{array}{l}\text { G1\% } \\
\text { S\% } \\
\text { G2/M\% }\end{array}$ & $\begin{array}{l}53.46 \pm 4.73 \\
34.17 \pm 3.47 \\
12.36 \pm 1.34\end{array}$ & $\begin{array}{r}51.60 \pm 1.04 \\
39.92 \pm 0.76 \\
8.48 \pm 0.49\end{array}$ & $\begin{array}{l}51.45 \pm 2.75 \\
34.21 \pm 2.70 \\
13.33 \pm 0.62^{\star}\end{array}$ \\
\hline \multicolumn{4}{|l|}{$48 \mathrm{~h}$} \\
\hline $\begin{array}{l}\text { G1\% } \\
\text { S\% } \\
\text { G2/M\% }\end{array}$ & $\begin{array}{l}52.49 \pm 2.10 \\
34.20 \pm 2.36 \\
13.31 \pm 0.89\end{array}$ & $\begin{array}{r}51.85 \pm 3.06 \\
38.36 \pm 2.24 \\
9.79 \pm 0.96\end{array}$ & $\begin{array}{l}50.58 \pm 3.05 \\
36.95 \pm 2.14 \\
12.47 \pm 1.01\end{array}$ \\
\hline \multicolumn{4}{|l|}{$72 \mathrm{~h}$} \\
\hline $\begin{array}{l}\mathrm{G} 1 \% \\
\mathrm{~S} \% \\
\mathrm{G} 2 / \mathrm{M} \%\end{array}$ & $\begin{array}{l}55.49 \pm 3.34 \\
33.06 \pm 2.39 \\
11.46 \pm 2.05\end{array}$ & $\begin{array}{r}49.76 \pm 3.95 \\
40.64 \pm 3.34 \\
9.60 \pm 0.86\end{array}$ & $\begin{array}{l}52.20 \pm 4.16 \\
37.28 \pm 3.33 \\
10.52 \pm 1.63\end{array}$ \\
\hline $\begin{array}{l}\text { Abbreviati } \\
\text { medium. } \\
\text { cell cycle } \\
\text { SCM. }\end{array}$ & $\begin{array}{l}\text { radiation-con } \\
\text { re cultured in } \\
\text { was determin }\end{array}$ & $\begin{array}{l}\text { nedium; SCM = } \\
\text { tioned medium } \\
\text { N cytometry. * }\end{array}$ & $\begin{array}{l}\text { radiation-condition } \\
48 \text { and } 72 h \text {, then } \\
\text { nts } P \text {-value }<0.05\end{array}$ \\
\hline
\end{tabular}

found a 1.2 -fold increase in the amount of TGF- $\beta 1$ released from irradiated cells $18 \mathrm{~h}$ after irradiation, indicating TGF- $\beta 1$ secretion at $18 \mathrm{~h}$ but not $1 \mathrm{~h}$ after irradiation. Moreover, when the irradiated cells were pretreated with SB431542 before irradiation, the increase in the amount of TGF- $\beta 1$ in 18 -h RCM was abolished (Figure $2 \mathrm{~A}$ ).

By pretreating signalling cells with SB431542 before irradiation, we found that the percentage of bystander cells with 53BP1 foci in 1-h RCM was back to the level in SCM (Figure 2B), and the proliferation inhibition in bystander cells in 18-h RCM was eliminated from $15 \%$ to $3 \%$ (Figure $2 \mathrm{C}$ ). The findings suggested that inhibiting the TGF- $\beta 1$ pathway in signalling cells abolished DNA damage and proliferation inhibition in bystander cells. After adding SB431542 into conditioned medium before transfer, we found that SB431542 at $10 \mu \mathrm{M}$ alone did not significantly affect the percentage of H1299 cells with 53BP1 foci (Figure 2B) and cell proliferation (data not shown). However, in the presence of SB431542, the percentage of bystander cells with 53BP1 foci in 1-h RCM was back to the level in SCM (Figure 2B), and the proliferation inhibition in $\mathrm{H} 1299$ bystander cells was attenuated from 15\% to 5\% (Figure $2 \mathrm{C}$ ). The data suggested that inhibiting the TGF- $\beta 1$ pathway in bystander cells also abolished the DNA damage and proliferation inhibition in bystander cells. These results indicated that the TGF- $\beta 1$ signalling pathways in both irradiated signalling and bystander cells were critical to induction of bystander effects.

Increase in the ROS level in bystander cells was dependent on the TGF- $\beta 1$ signalling pathway. We first measured the ROS levels in bystander cells. As shown in Figure 3A, compared with in fresh medium, the intracellular ROS levels decreased by $18 \%$ $(P=0.030)$ or $8 \%(P=0.35)$, respectively, after cells were cultured in 1-h SCM or 1-h RCM for $1 \mathrm{~h}$. Thus, the ROS levels in bystander cells cultured in 1 -h RCM was $12 \%(P=0.014)$ greater than that in 1-h SCM (Figure 3A). In addition, the ROS levels in bystander cells also dropped below the normal level after cultured in 18-h SCM or 18-h RCM for $1 \mathrm{~h}$, but there was no significant difference between 18-h SCM and 18-h RCM (Figure 3A). The results suggested that RCM collected at $1 \mathrm{~h}$ and $18 \mathrm{~h}$ activated different responses in bystander cells.

We also measured the level of oxidative DNA damage in bystander cells. As shown in Figure 3C, compared with in fresh medium, the level of oxidative DNA damage of cells decreased obviously after cultured in 1 -h SCM for $1 \mathrm{~h}$, but remained similar in 1-h RCM. Bystander cells in 1-h RCM showed more significant oxidative DNA damage than cells in 1-h SCM. Thus, the changes in oxidative DNA damage were in accordance with the changes in ROS level in cells cultured with $1 \mathrm{~h}$ conditioned medium. In addition, our unpublished data showed no obvious oxidative DNA damage in bystander cells in 18-h RCM (data not shown), which agreed with no increase in ROS levels with 18-h RCM culture (Figure 3A).

In addition, when signalling cells were treated with SB431542 $1 \mathrm{~h}$ before irradiation, the generated conditioned medium failed to cause an increase in the ROS levels in bystander cells (Figure 3A), suggesting that activating the TGF- $\beta 1$ pathway in signalling cells was critical to the increase in ROS levels in bystander cells. Moreover, when SB431542 was added into 1-h RCM, no increase in the ROS levels in bystander cells was detected (Figure 3A), indicating that the increase in ROS levels in bystander cells was dependent on activation of their TGF- $\beta 1$ pathway after cultured in RCM.

miR-21 was involved in the bystander response and was dependent on the TGF- $\boldsymbol{\beta} \mathbf{1}$ pathway. We detected the expression of miR-21 in bystander cells in different medium. There was a 2.5-fold increase in the miR-21 level in bystander cells after cultured in 1-h RCM for $1 \mathrm{~h}$ compared with in 1-h SCM (Figure 4A). In contrast, when bystander cells were cultured in 18-h RCM for $1 \mathrm{~h}$, their miR-21 expression was reduced by approximately $40 \%$ compared with in 18-h SCM (Figure 4B). These results indicated that miR-21 was involved in the radiationinduced bystander response, and its alterations were dependent on the time at which RCM was harvested post irradiation.

We then assessed whether alterations in miR-21 expression in bystander cells were dependent on the TGF- $\beta 1$ pathway. When the TGF- $\beta 1$ pathway in signalling cells was inhibited by SB431542, the generated 1-h SCM and 1-h RCM increased miR-21 expression in bystander cells compared with in the absence of SB431542, but the difference of miR-21 expression in bystander cells in 1-h RCM and in 1-h SCM was significantly attenuated (Figure 4A). The generated 18-h SCM and 18-h RCM also increased miR-21 expression in bystander cells; however, 18-h RCM caused a greater increase than 18-h SCM, thus the reduction of miR-21 expression in bystander cells in 18-h RCM compared with in 18-h SCM observed in the absence of SB431542 disappeared (Figure 4B). When the TGF- $\beta 1$ pathway in bystander cells was inhibited by adding SB431542 into conditioned medium, we found that SB431542 alone caused about 2.5-fold increase in miR-21 expression in cells, but the difference of miR-21 expression in bystander cells in 1-h SCM and 1-h RCM observed in the absence of SB431542 decreased by 50\% (Figure 4A). Similarly, inhibition of the TGF- $\beta 1$ pathway in bystander cells resulted in abolishment of the reduction of miR-21 expression in bystander cells in 18-h RCM compared with in 18-h SCM in the absence of SB431542 (Figure 4B). These data suggested that the alterations of miR-21 expression in bystander cells were dependent on the TGF- $\beta 1$ pathways in both signalling and bystander cells.

miR-21 was an important mediator of the RIBEs. To determine the role of miR-21 in RIBEs, we tested whether exogenous miR-21 regulation in bystander cells would modulate bystander effects. The data show that transfection of a miR-21 mimic into cells resulted in an approximately 30 - and 15-fold increase in miR-21 level at 24 and $72 \mathrm{~h}$ after transfection, respectively (Figure $5 \mathrm{~A}$ ), and transfection of a miR-21 inhibitor led to a $75 \%$ and $22 \%$ decrease in miR-21 expression at 24 and $72 \mathrm{~h}$, respectively (Figure 5B).

On one hand, upregulation of miR-21 alone increased the percentage of cells with 53BP1 foci by $17 \%$ (Figure 5C). This was in accordance with the increased miR-21 level and induction of 53BP1 foci in bystander cells in 1-h RCM. When the bystander cells transfected with miR-21 inhibitor were cultured in 1-h RCM, no 

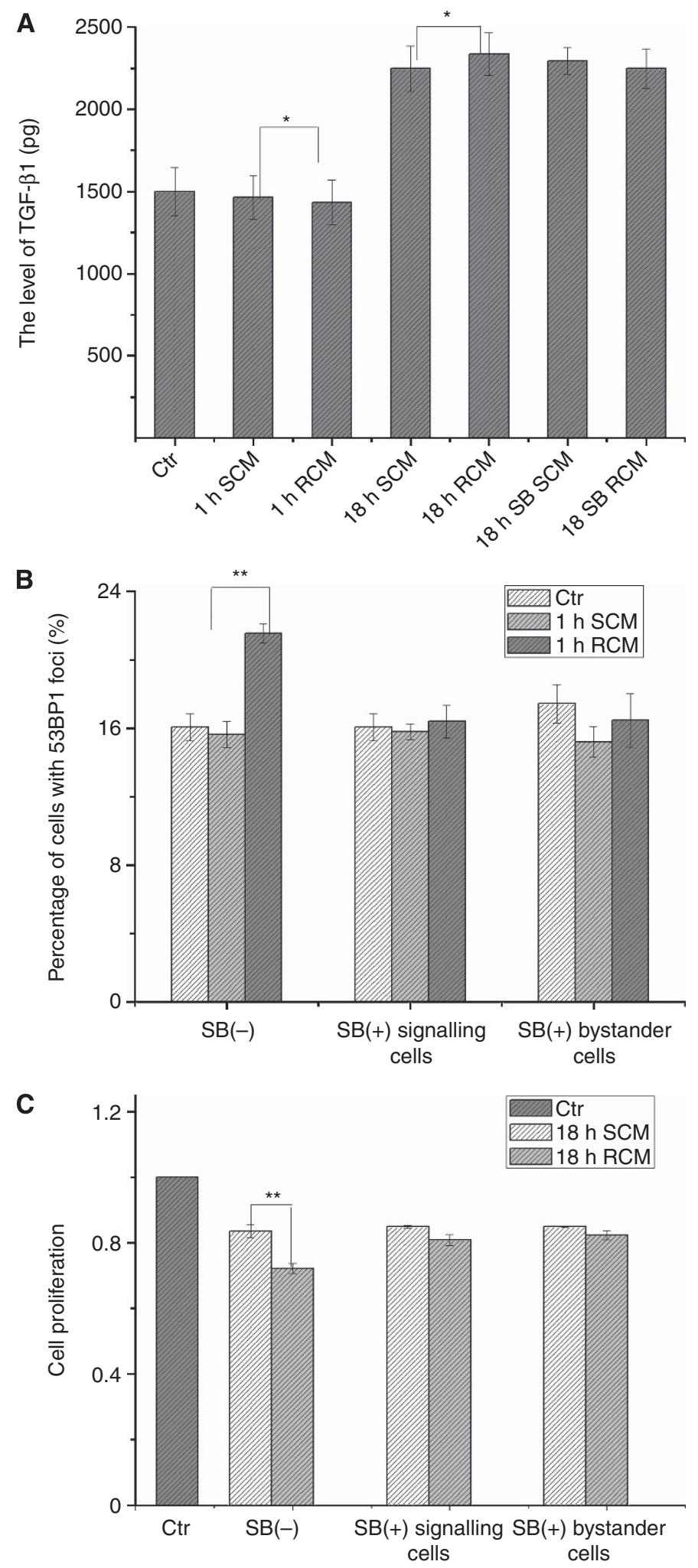

Figure 2. The TGF- $\beta 1$ signaling pathway was involved in bystander response in H1299 cells. (A) The amount of TGF- $\beta 1$ in the H1299 cell medium at different times post irradiation in the absence or presence of TGF- $\beta 1$ signalling inhibitor SB431542; (B) the effect of SB431542 on the induction of 53BP1 foci in bystander cells after cultured in 1-h RCM for $1 \mathrm{~h} ;(\mathbf{C})$ the effect of SB431542 on proliferation inhibition in bystander cells after cultured in 18-h RCM for $48 \mathrm{~h}$. 'SB ( - )' represents samples without SB431542, 'SB (+) signalling cells' represents that SB431542 was added to signalling cells $1 \mathrm{~h}$ before irradiation and 'SB $(+)$ bystander cells' represents that SB431542 was added into RCM before transferred to bystander cells. * represents $P$-value $<0.05$ vs relative SCM. ** represents $P$-value $<0.01$ vs relative SCM.

induction of 53BP1 foci was observed (Figure 5C). Moreover, downregulation of miR-21 significantly attenuated the ROS levels in bystander cells cultured with 1-h RCM back to that with 1-h SCM
(Figure 5D). The results indicated that elevated miR-21 expression in bystander cells led to the increase in the ROS levels and DNA damage. 
A

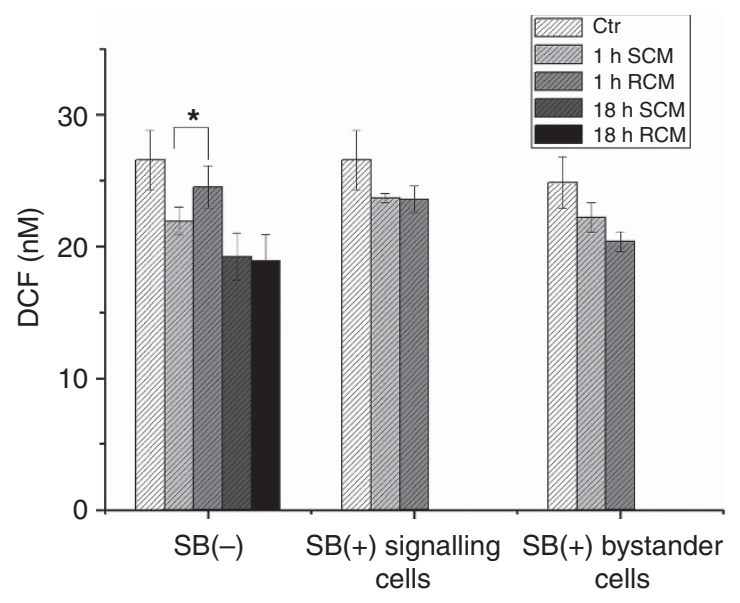

B
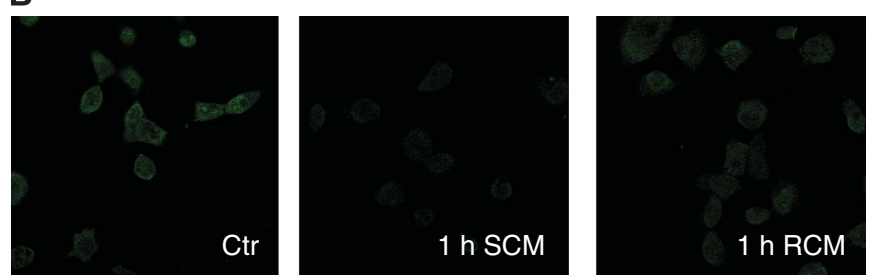

C

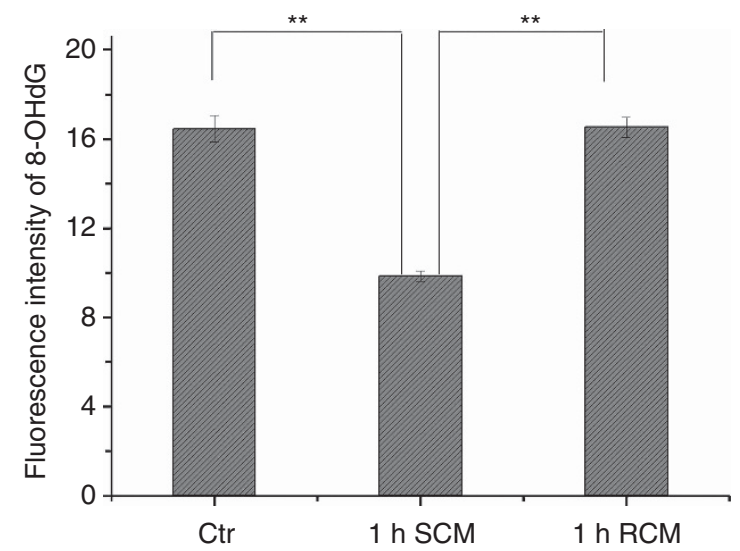

Figure 3. Increase of ROS level and oxidative damage in bystander cells was dependent on TGF- $\beta 1$ signalling pathways. (A) ROS levels in $\mathrm{H} 1299$ cells cultured in conditioned medium for $1 \mathrm{~h}$ in the absence or presence of SB431542. SB431542 was either added to signalling cells $1 \mathrm{~h}$ before irradiation or added into RCM before transferred to bystander cell; (B) in situ immunofluorescence images of 8-hydroxy-2'deoxyguanosine (8-OHdG) in bystander cells cultured with $1 \mathrm{~h}$ conditioned medium for $1 \mathrm{~h}$; (C) the level of oxidative DNA damage in $\mathrm{H} 1299$ cells cultured in $1 \mathrm{~h}$ conditioned medium for $1 \mathrm{~h}$. * represents $P$-value $<0.05$ vs relative control. ${ }^{* \star}$ represents $P$-value $<0.01$ vs relative control.

On the other hand, when the miR-21 levels in cells were downregulated by transfection with a miR-21 inhibitor, the proliferation was reduced by $18 \%$ compared with the relative control cells transfected with negative inhibitor (Figure 5E). This was in accordance with the decreased miR-21 levels and proliferation inhibition in bystander cells cultured in 18-h RCM. Furthermore, when the bystander cells transfected with miR-21 mimics were cultured in 18-h RCM, the proliferation was back to the level in cells cultured in 18-h SCM (Figure 5E). The results indicated that the decreased miR-21 levels in bystander cells inhibited the cell proliferation.
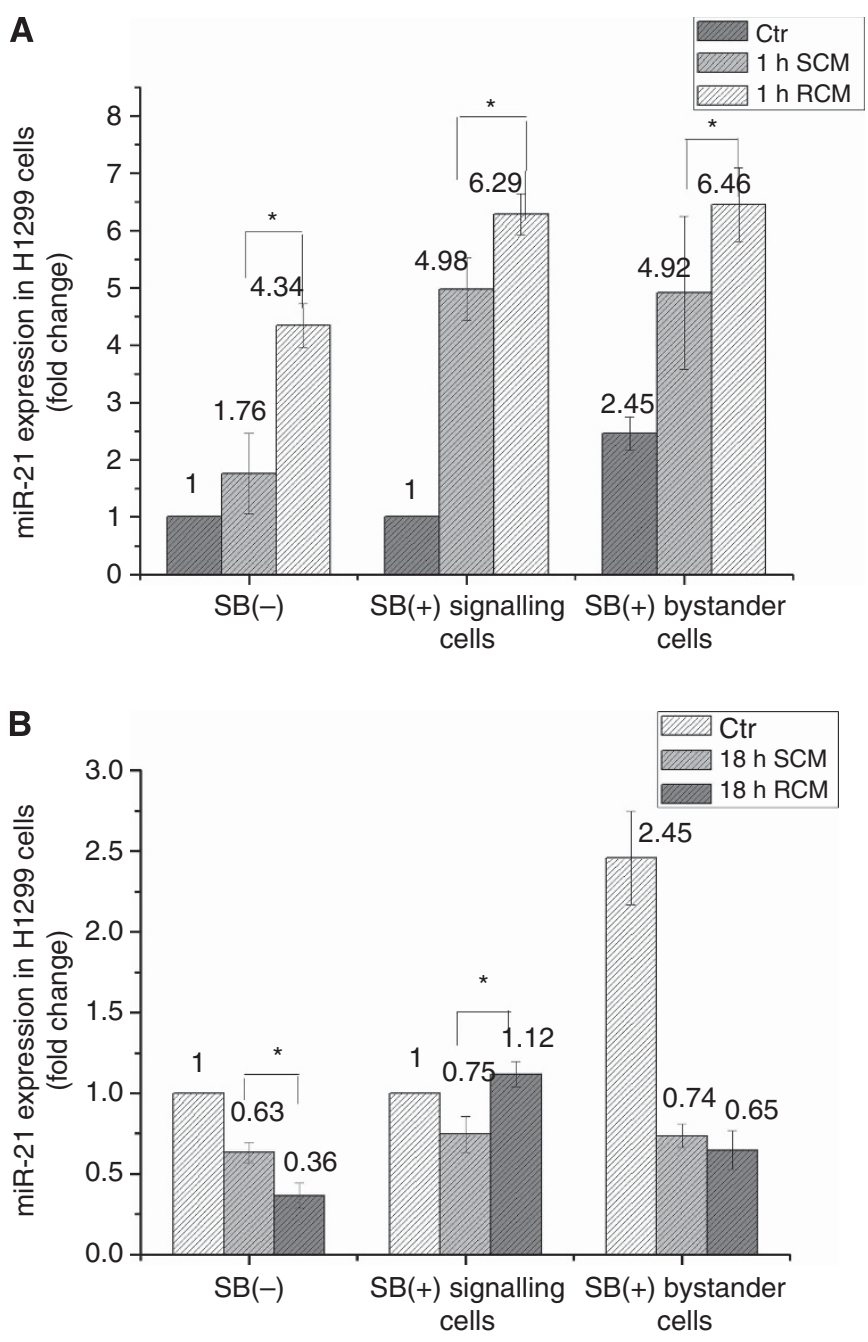

Figure 4. miR-21 was involved in bystander response and was dependent on the TGF- $\beta 1$ pathway. The alterations of miR-21 expression in bystander cells cultured in conditioned medium harvested at different times post irradiation in the absence or presence of SB431542 was determined by reverse transcriptase-PCR. SB431542 was either added to signalling cells $1 \mathrm{~h}$ before irradiation or added into RCM before transferred to bystander cells. (A) One-hour conditioned medium; (B) 18-h conditioned medium. * represents $P$-value $<0.05$ vs relative control.

\section{DISCUSSION}

In the present study, we demonstrated that X-irradiation could induce medium-mediated bystander effects in H1299 cells. Moreover, RCM harvested at different times post irradiation caused completely different biological changes. One-hour RCM induced elevated miR-21 expression, increased ROS levels and DNA damage in bystander cells, while 18-h RCM resulted in reduced miR-21 level and inhibited proliferation in bystander cells. This result is similar to that in a previous study (Zhang et al, 2009) showing that the radiation-induced bystander mutation was dependent on the time point at which conditioned medium was harvested. Furthermore, our results suggested that at different times post irradiation, bystander cells received different signals from irradiated cells that were in different stages of DNA damage response, thus activating different pathways and yielding different changes at the cellular level. In spite of a large body of evidence supporting the occurrence of RIBEs, there is some debate regarding whether RIBEs are universal 

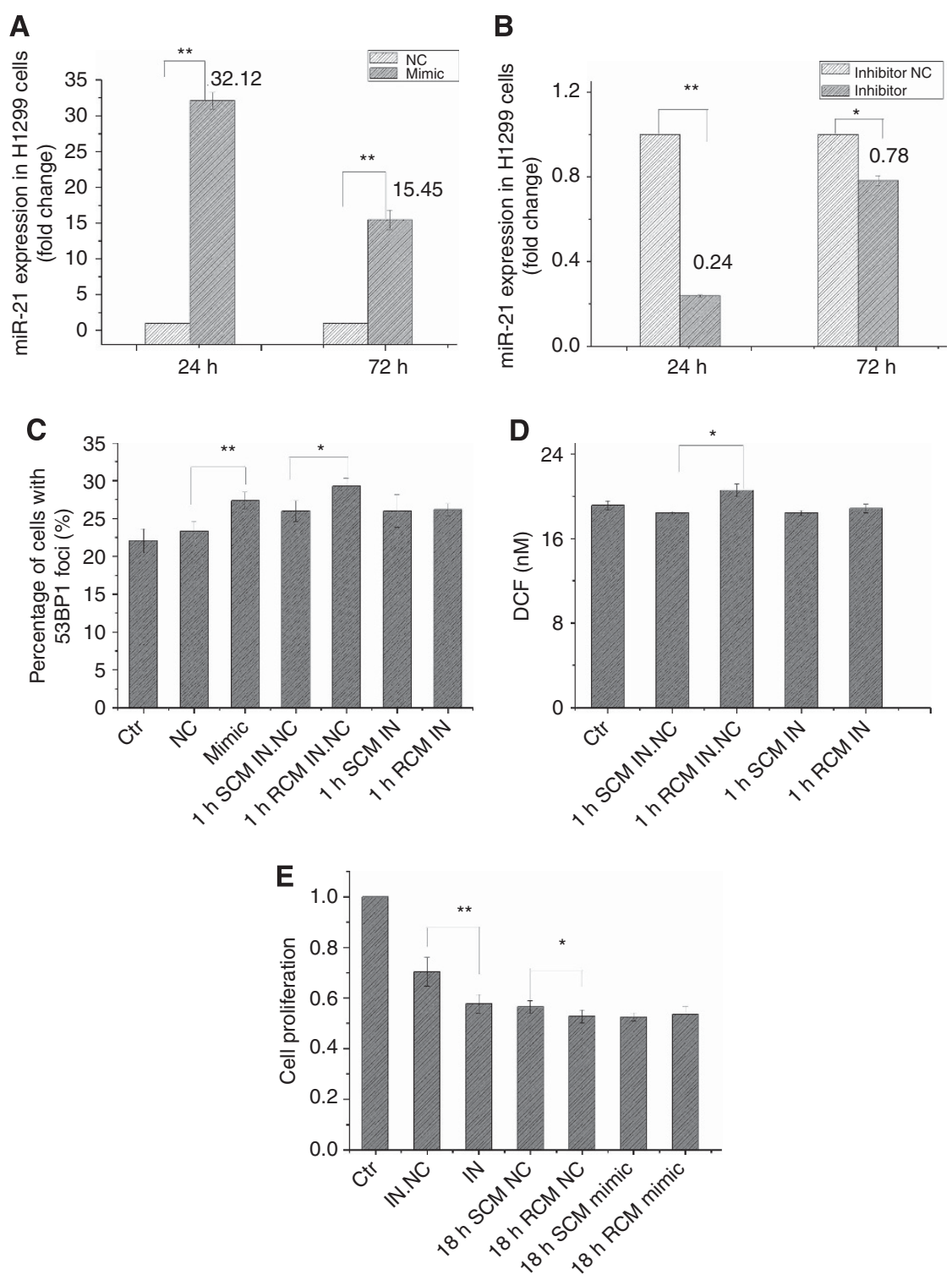

Figure 5. miR-21 was an important mediator of radiation-induced bystander response in H1299 cells. (A) Overexpression of miR-21 in cells 24 and $72 \mathrm{~h}$ after miR-21 mimic transfection; (B) downregulation of miR-21 in cells 24 and $72 \mathrm{~h}$ after miR-21 inhibitor transfection; (C) induction of $53 \mathrm{BP} 1$ foci in bystander cells with downregulated miR-21 cultured in 1-h RCM for $1 \mathrm{~h}$; (D) ROS levels in bystander cells with downregulated miR-21 cultured in 1-h RCM for $1 \mathrm{~h}$; (E) cell proliferation of bystander cells with upregulated miR-21cultured in 18-h RCM for $48 \mathrm{~h}$. Mimic and IN represent miR-21 mimic and inhibitor, respectively. NC and IN.NC represent negative control for miR-21 mimic and miR-21 inhibitor, respectively.

* represents $P$-value $<0.05$ vs relative control. ** represents $P$-value $<0.01$ vs relative SCM.

(Groesser et al, 2008; Sowa et al, 2010). Besides the possible explanations for why RIBEs were not observed in some tested systems, such as the epigenetic status of a specific cell line or the precise culture conditions and medium supplements (Groesser et al, 2008; Sowa et al, 2010), our results suggested that appropriate end point examined at appropriate time could be an important factor.

TGF- $\beta 1$ has been shown to mediate RIBEs (Iyer et al, 2000; Shao et al, 2008; Gow et al, 2010; Temme and Bauer, 2013). TGF- $\beta 1$ can be released from irradiated cells into conditioned medium and can diffuse freely to unirradiated cells to induce bystander effects (Shao et al, 2008). This may be the case in our experiment with 18-h RCM, where elevated TGF- $\beta 1$ levels were detected. However, when bystander cells were cultured in 1-h RCM, where no TGF- $\beta 1$ release from irradiated cells was observed, bystander DNA damage occurred. It suggests that active TGF- $\beta 1$ in conditioned medium was not necessary for the induction of bystander DNA damage. When we pretreated irradiated cells with SB431542, the bystander effects were completely abolished. This result suggests that the TGF- $\beta 1$ signalling pathway in irradiated cells was critical to RIBEs regardless of their status of active TGF- $\beta 1$ secretion. Similarly, when we added SB431542 into RCM, the bystander effects were attenuated. This result suggests that the TGF- $\beta 1$ signalling pathway in bystander cells could be activated by bystander signalling factors in RCM, thereby mediating RIBEs.

miRNA modulation has been shown to be involved in RIBEs (Koturbash et al, 2008; Kovalchuk et al, 2010; Chaudhry and Omaruddin, 2012). But Dickey et al (2011) reported that miRNAs did not seem to be the primary signalling factor associated with bystander DNA damage. Therefore, the roles of miRNAs in bystander signalling remain to be explored.

We report here for the first time that miR-21 acted as an important mediator of RIBEs. Interestingly, miR-21 of bystander cells dysregulated differently after cultured in RCM harvested at different times post irradiation (that is, it was elevated when bystander cells were in 1-h RCM, but was decreased in 18-h RCM). 
Most importantly, elevated miR-21 levels of bystander cells cultured in 1-h RCM seemed to be critical to the increase in ROS levels and bystander DNA damage, as these effects were abolished when miR-21 was downregulated in bystander cells before cultured in RCM. It has been reported that overexpression of miR-21 can significantly repress the production of superoxide dismutase 2 in cells, which results in increased intracellular ROS levels (Fleissner et al, 2010). Moreover, Zhang et al (2012) recently revealed that miR-21 regulates cellular ROS levels by directly attenuating superoxide dismutase 3 or by indirectly reducing superoxide dismutase 2 levels through tumour necrosis factor- $\alpha$. Our data also show a reduced superoxide dismutase 2 expression in cells in 1-h RCM compared with in 1-h SCM (Jiang et al, 2014). Furthermore, when bystander cells were under oxidative stress, DNA damage occurred. On the other hand, the proliferation inhibition in bystander cells cultured in 18-h RCM was related to the decreased miR-21 expression. This is in agreement with previous reports demonstrating that the upregulation of miR-21 promotes cell growth and blocking miR-21 leads to proliferation inhibition (Gong et al, 2011; Huang et al, 2013). Therefore, differential dysregulation of miR-21 may explain why bystander cells cultured in RCM harvested at different times post irradiation expressed different changes at the cellular level. This indicates an important mediating role for miR-21 in the induction of RIBEs.

We have also found that dysregulation of miR-21 in bystander cells was dependent on TGF- $\beta 1$ signalling pathways in both signalling and bystander cells. The relationship between TGF- $\beta 1$ and miR-21 seems complicated. On one hand, miR-21 can have both positive and negative effects on the regulation of TGF- $\beta 1$ signalling (Liu et al, 2011; Bhagat et al, 2013). On the other hand, miR-21 can be induced by TGF- $\beta 1$ (Liu et al, 2011), TGF- $\beta 1 / \mathrm{smad}$ signalling can act as a critical upstream regulator of miR-21 (Wang et al, 2012). Our results indicated that the TGF- $\beta 1$ signalling pathway in bystander cells regulated miR-21 differently at different times. While 1-h RCM caused miR-21 upregulation in bystander cells, 18-h RCM induced miR-21 downregulation in bystander cells. Since the addition of SB431542 into RCM diminished bystander effects in both situations, it is suggested that the TGF- $\beta 1$ pathway was activated in bystander cells cultured with either 1-h or 18 -h RCM. However, the reason why the activated TGF- $\beta 1$ pathway caused different changes in miR-21 expression in bystander cells is unknown. One possible explanation is that the signals triggering activation of the TGF- $\beta 1$ pathway in bystander cells at different time may be different. Moreover, Figure 4 shows that while the downregulation of miR-21 induced by $18-\mathrm{h} \mathrm{RCM}$ is abolished by adding SB431542 into RCM, 1-h RCM-induced miR-21 upregulation is only partially attenuated in the presence of SB431542, suggesting that the upstream regulators other than the TGF- $\beta 1$ pathway may be involved in the increase in miR-21 expression of bystander cells cultured in 1-h RCM.

In summary, the conditioned medium from irradiated H1299 human lung cancer cells induces different biological changes in bystander cells at different times post irradiation. The activation of the TGF- $\beta 1$ pathway in irradiated cells is involved in bystander signalling. Moreover, the TGF- $\beta 1-\mathrm{miR}-21-\mathrm{ROS}$ pathway in bystander cells is critical for the manifestation of bystander responses. Figure 6 illustrates our proposed working model of the radiation-induced bystander signalling pathway involved. When cells are irradiated, the TGF- $\beta 1$ pathway becomes activated and cells release some signalling molecules including TGF- $\beta 1$ into the medium. These signalling molecules diffuse to bystander cells and activate the TGF- $\beta 1$ pathway in bystander cells. Depending on the time at which RCM is harvested post irradiation, the activated TGF- $\beta 1$ pathway can either upregulate or downregulate miR-21 expression in bystander cells. The increased miR-21 levels then cause oxidative stress in bystander cells, leading to DNA damage. On the other hand, decreased miR-21 levels induce cell cycle delay

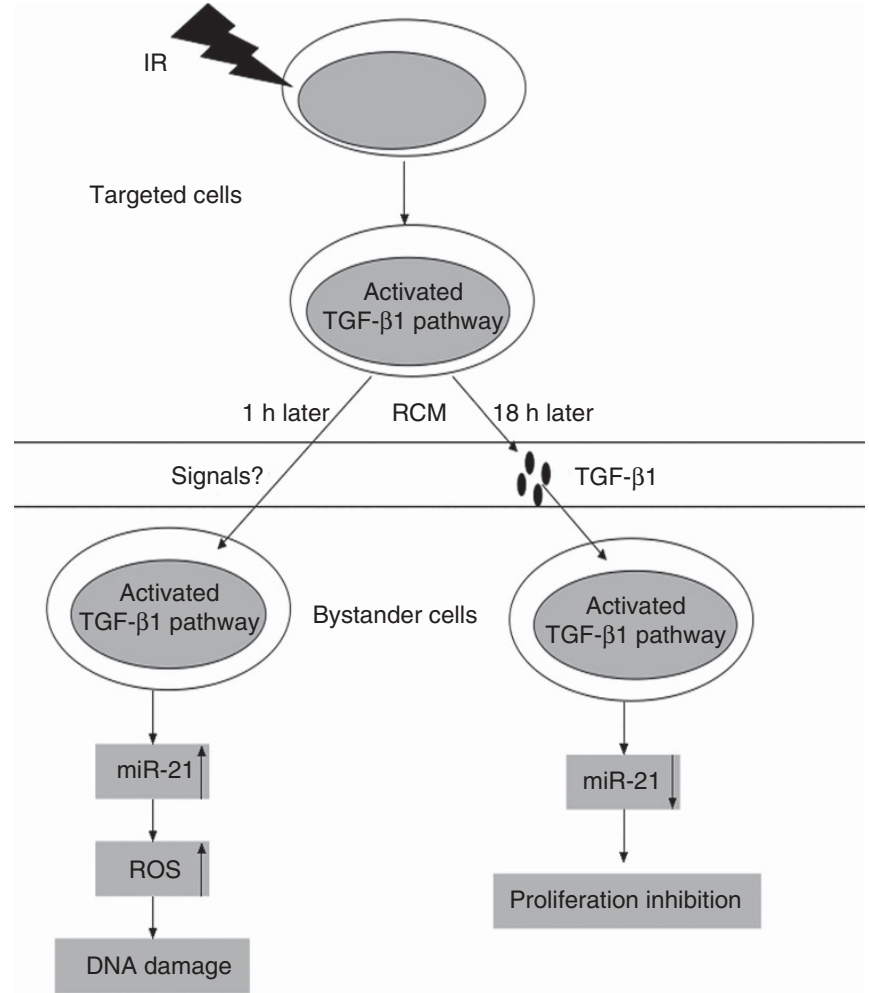

Figure 6. Schematic drawing of the proposed working model for radiation-induced bystander effects.

and proliferation inhibition. However, there are still some unanswered questions regarding this bystander signalling pathway. For example, what is (are) the signalling molecule (s) in 1-h RCM responsible for activating the TGF- $\beta 1$ pathway in bystander cells? Although the TGF- $\beta 1$ pathway can be activated in bystander cells cultured in RCM harvested at different times post irradiation, why does it dysregulate miR-21 differently, which in turn causes different changes at the cellular level? These questions warrant further investigation.

\section{ACKNOWLEDGEMENTS}

We thank Professor Tom K. Hei of Columbia University for his critical reading of this manuscript. This research was supported in part by the National Natural Science Foundation of China (grant No. 31270898 and 11335011), the Key programs of Natural Science Foundation of Jiangsu Educational Committee (12KJA310005), Beijing Key Laboratory of DNA Damage Response (BKL-DDR) open funding and the Priority Academic Program Development of Jiangsu Higher Education Institution (PARD).

\section{REFERENCES}

Aravindan N, Aravindan S, Pandian V, Khan FH, Ramraj SK, Natt P, Natarajan M (2014) Acquired tumor cell radiation resistance at the treatment site is mediated through radiation-orchestrated intercellular communication. Int J Radiat Oncol Biol Phys 88(3): $677-685$.

Asaithamby A, Chen DJ (2009) Cellular responses to DNA double-strand breaks after low-dose $\gamma$-irradiation. Nucleic Acids Res 37: 3912-3923.

Azzam EI, de Toledo SM, Little JB (2001) Direct evidence for the participation of gap junction-mediated intercellular communication in the transmission 
of damage signals from alpha -particle irradiated to nonirradiated cells. Proc Natl Acad Sci USA 98: 473-478.

Azzam EI, De Toledo SM, Spitz DR, Little JB (2002) Oxidative metabolism modulates signal transduction and micronucleus formation in bystander cells from alpha-particle-irradiated normal human fibroblast cultures. Cancer Res 62: 5436-5442.

Bhagat TD, Zhou L, Sokol L, Kessel R, Caceres G, Gundabolu K, Tamari R, Gordon S, Mantzaris I, Yu Y (2013) miR-21 mediates hematopoietic suppression in MDS by activating TGF- $\beta$ signaling. Blood 121: 2875-2881.

Burdak-Rothkamm S, Short SC, Folkard M, Rothkamm K, Prise KM (2007) ATR-dependent radiation-induced gamma $\mathrm{H} 2 \mathrm{AX}$ foci in bystander primary human astrocytes and glioma cells. Oncogene 26: 993-1002.

Chaudhry MA, Omaruddin RA (2012) Differential regulation of microRNA expression in irradiated and bystander cells. Mol Biol (Mosk) 46: 634-643.

Dickey JS, Zemp FJ, Altamirano A, Sedelnikova OA, Bonner WM, Kovalchuk O (2011) H2AX phosphorylation in response to DNA double-strand break formation during bystander signalling: effect of microRNA knockdown. Radiat Prot Dosimetry 143: 264-269.

Fleissner F, Jazbutyte V, Fiedler J, Gupta SK, Yin X, Xu Q, Galuppo P, Kneitz S, Mayr M, Ertl G, Bauersachs J, Thum T (2010) Short communication: asymmetric dimethylarginine impairs angiogenic progenitor cell function in patients with coronary artery disease through a microRNA-21-dependent mechanism. Circ Res 107: 138-143.

Gong C, Yao Y, Wang Y, Wu W, Chen J, Yao H, Song E (2011) Up-regulation of miR-21 mediates resistance to trastuzumab therapy for breast cancer. J Biol Chem 286: 19127-19137.

Gow MD, Seymour CB, Ryan LA, Mothersill CE (2010) Induction of bystander response in human glioma cells using high-energy electrons: a role for TGF-beta1. Radiat Res 173: 769-778.

Groesser T, Cooper B, Rydberg B (2008) Lack of bystander effects from highLET radiation for early cytogenetic end points. Radiat Res 170: 794-802.

Harada K, Nonaka T, Hamada N, Sakurai H, Hasegawa M, Funayama T, Kakizaki T, Kobayashi Y, Nakano T (2009) Heavy-ion-induced bystander killing of human lung cancer cells: role of gap junctional intercellular communication. Cancer Sci 100: 684-688.

Hei TK, Zhou H, Chai Y, Ponnaiya B, Ivanov VN (2011) Radiation induced non-targeted response: mechanism and potential clinical implications. Curr Mol Pharmacol 4: 96-105.

Herok R, Konopacka M, Polanska J, Swierniak A, Rogolinski J, Jaksik R, Hancock R, Rzeszowska-Wolny J (2010) Bystander effects induced by medium from irradiated cells: similar transcriptome responses in irradiated and bystander K562 cells. Int J Radiat Oncol Biol Phys 77: 244-252.

Huang TH, Wu F, Loeb GB, Hsu R, Heidersbach A, Brincat A, Horiuchi D, Lebbink RJ, Mo YY, Goga A, McManus MT (2013) Up-regulation of miR-21 by HER2/neu signaling promotes cell invasion. J Biol Chem 284: $18515-18524$

Ilnytskyy Y, Kovalchuk O (2011) Non-targeted radiation effects-an epigenetic connection. Mutat Res 714: 113-125.

Ivanov VN, Zhou H, Karasic TB, Yaghoubian B, Hei TK (2010) Radiationinduced bystander signaling pathways in human fibroblasts: a role for interleukin-33 in the signal transmission. Cell Signal 22: 1076-1087.

Iyer R, Lehnert BE, Svensson R (2000) Factors underlying the cell growthrelated bystander responses to alpha particles. Cancer Res 60: 1290-1298.

Jain MR, Li M, Chen W, Liu T, de Toledo SM, Pandey BN, Li H, Rabin BM, Azzam EI (2011) In vivo space radiation-induced non-targeted responses: late effects on molecular signaling in mitochondria. Curr Mol Pharmacol 4: $106-114$.

Jiang Y, Tian W, Yin X, Wang J, Yang H (2014) The adaptive response to X-irradiation in H1299 bystander cells is associated with TGF- $\beta 1$ pathway. J Radiat Res Radiat Process 32: 030205.

Koturbash I, Rugo RE, Hendricks CA, Loree J, Thibault B, Kutanazi K, Pogribny I, Yanch JC, Engelward BP, Kovalchuk O (2006) Irradiation induces DNA damage and modulates epigenetic effectors in distant bystander tissue in vivo. Oncogene 25: 4267-4275.

Koturbash I, Zemp FJ, Kutanzi K, Luzhna L, Loree J, Kolb B, Kovalchuk O (2008) Sex-specific microRNAome deregulation in the shielded bystander spleen of cranially exposed mice. Cell Cycle 7: 1658-1667.

Koturbash I, Boyko A, Rodriguez-Juarez R, McDonald RJ, Tryndyak VP, Kovalchuk I, Pogribny IP, Kovalchuk O (2007) Role of epigenetic effectors in maintenance of the long-term persistent bystander effect in spleen in vivo. Carcinogenesis 28: 1831-1838.
Kovalchuk O, Baulch JE (2008) Epigenetic changes and nontargeted radiation effects-is there a link? Environ Mol Mutagen 49: 16-25.

Kovalchuk O, Zemp FJ, Filkowski JN, Altamirano AM, Dickey JS, Jenkins-Baker G, Marino SA, Brenner DJ, Bonner WM, Sedelnikova OA (2010) microRNAome changes in bystander three-dimensional human tissue models suggest priming of apoptotic pathways. Carcinogenesis 31: 1882-1888.

Liu C, Li B, Cheng Y, Lin J, Hao J, Zhang S, Mitchel RE, Sun D, Ni J, Zhao L, Gao F, Cai J (2011) MiR-21 plays an important role in radiation induced carcinogenesis in $\mathrm{BALB} / \mathrm{c}$ mice by directly targeting the tumor suppressor gene Big-h3. Int J Biol Sci 7: 347-363.

Lyng FM, Seymour CB, Mothersill C (2002) Initiation of apoptosis in cells exposed to medium from the progeny of irradiated cells: a possible mechanism for bystander-induced genomic instability? Radiat Res 157: 365-370.

Mancuso M, Pasquali E, Leonardi S, Tanori M, Rebessi S, Majo VD, Pazzaglia S, Toni MP, Pimpinella M, Covelli V, Saran A (2008) Oncogenic bystander radiation effects in Patched heterozygous mouse cerebellum. Proc Natl Acad Sci USA 105: 12445-12450.

McMahon SJ, Butterworth KT, Trainor C, McGarry CK, O'Sullivan JM, Schettino G, Hounsell AR, Prise KM (2013) A kinetic-based model of radiation-induced intercellular signalling. PLoS One 8: e54526.

Moiseeva O, Bourdeau V, Roux A, Deschênes-Simard X, Ferbeyre G (2009) Mitochondrial dysfunction contributes to oncogene-induced senescence. Mol Cell Biol 29: 4495-4507.

Mothersill C, Seymour C (2012) Are epigenetic mechanisms involved in radiation-induced bystander effects? Front Genet 3: 74.

Nagasawa H, Little JB (1992) Induction of sister chromatid exchanges by extremely low doses of alpha-particles. Cancer Res 52: 6394-6396.

Rzeszowska-Wolny J, Herok R, Widel M, Hancock R (2009) X-irradiation and bystander effects induce similar changes of transcript profiles in most functional pathways in human melanoma cells. DNA Repair (Amst) 8: 732-738.

Shao C, Folkard M, Michael BD, Prise KM (2004) Targeted cytoplasmic irradiation induces bystander responses. Proc Natl Acad Sci USA 101: $13495-13500$.

Shao C, Folkard M, Prise KM (2008) Role of TGF-betal and nitric oxide in the bystander response of irradiated glioma cells. Oncogene 27: 434-440.

Simone NL, Soule BP, Ly D, Saleh AD, Savage JE, Degraff W, Cook J, Harris CC, Gius D, Mitchell JB (2009) Ionizing radiation-induced oxidative stress alters miRNA expression. PLoS One 4: e6377.

Sowa MB, Goetz W, Baulch JE, Pyles DN, Dziegielewski J, Yovino S, Snyder AR, de Toledo SM, Azzam EI, Morgan WF (2010) Lack of evidence for low-LET radiation induced bystander response in normal human fibroblasts and colon carcinoma cells. Int J Radiat Biol 86: 102-113.

Temme J, Bauer G (2013) Low-dose gamma irradiation enhances superoxide anion production by nonirradiated cells through TGF- $\beta 1$-dependent bystander signaling. Radiat Res 179: 422-432.

Wang J, Li Y, Wang X, Jiang C (2012) Ursolic acid inhibits proliferation and induces apoptosis in human glioblastoma cell lines U251 by suppressing TGF- $\beta 1 /$ miR-21/PDCD4 pathway. Basic Clin Pharmacol Toxicol 111: 106-112.

Yang H, Asaad N, Held KD (2005) Medium-mediated intercellular communication is involved in bystander responses of X-ray-irradiated normal human fibroblasts. Oncogene 24: 2096-2103.

Yang H, Magpayo N, Held KD (2011) Targeted and non-targeted effects from combinations of low doses of energetic protons and iron ions in human fibroblasts. Int J Radiat Biol 87: 311-319.

Zhang X, Ng WL, Wang P, Tian L, Werner E, Wang H, Doetsch P, Wang Y (2012) MicroRNA-21 modulates the levels of reactive oxygen species by targeting SOD3 and TNF $\alpha$. Cancer Res 72: 4707-4713.

Zhang Y, Zhou J, Baldwin J, Held KD, Prise KM, Redmond RW, Liber HL (2009) Ionizing radiation-induced bystander mutagenesis and adaptation: quantitative and temporal aspects. Mutat Res 671: 20-25.

Zhou H, Suzuki M, Randers-Pehrson G, Vannais D, Chen G, Waldren CA, Hei TK (2001) Radiation risk to low fluences of alpha particles may be greater than we thought. Proc Natl Acad Sci USA 98: 14410-14415.

This work is published under the standard license to publish agreement. After 12 months the work will become freely available and the license terms will switch to a Creative Commons AttributionNonCommercial-Share Alike 3.0 Unported License. 